\title{
Processos fonológicos de motivação estilística em corpus poético do Português Arcaico'
}

\author{
Lívia Monteiro de Queiroz Migliorini \\ Universidade Estadual Paulista "Júlio de Mesquita Filho" (UNESP), \\ Assis, São Paulo, Brasil \\ liviamigliorini@gmail.com \\ https://orcid.org/0000-0003-0460-084X
}

DOI: http://dx.doi.org/10.21165/el.v47i1.2040

\section{Resumo}

Este artigo tem como objetivo analisar a ocorrência de processos fonológicos de cunho estilístico a partir de um corpus poético do Português Arcaico, as Cantigas de Santa Maria, atribuídas à lavra do Rei Afonso X de Castela, o rei "Sábio". Trata-se, portanto, de verificar os possíveis condicionamentos linguísticos envolvidos na sua realização, sobretudo no que se refere a fenômenos de sândi - crase, elisão e hiato, conforme a noção de opacidade proposta por Kiparsky (1985). Com base nos dados analisados, foi possível concluir que o trovador não possui tanta liberdade para "criar" ou não formas desviantes, segundo sua vontade, para satisfazer necessidades artísticas, fato corroborado pela baixíssima margem de arbítrio de que dispunham.

Palavras-chave: Português Arcaico; Cantigas de Santa Maria; processos fonológicos.

\section{Phonological processes of stylistic motivation in poetic corpus of Archaic Portuguese}

\begin{abstract}
This paper aims to analyze the occurence of stylistic phonological processes occurrence, or processes considered unexpected, from a corpus of Medieval Portuguese: The Cantigas de Santa Maria, attributed to Alfonso X of Castile, the "Wise" king. Possible linguistic constraints involved in their performance are analyzed particularly as regards the phenomena of sandhi crasis, elision and hiatus. From the data analysis, it was concluded that troubadours did not have so much freedom to "create" or not deviant forms according to their own will to satisfy artistic needs and this fact is corroborated by the very low margin of will available to them.
\end{abstract}

Keywords: Medieval Portuguese; The Cantigas de Santa Maria; phonological processes.

\section{Introdução}

O presente estudo tem como objetivo analisar processos fonológicos de motivação estilística, ou seja, processos fonológicos considerados não esperados, presentes em Cantigas de Santa Maria (de agora em diante, CSM), atribuídas ao rei Afonso X de Castela (1221-1284), o Rei "Sábio". Nesta investigação, em um primeiro momento, considera-se como processo estilístico (ou desvio) aquele fenômeno cuja realização não é esperada, o que inclui casos típicos de opacidade, conforme Kiparsky (1985). ${ }^{2}$ Todavia,

\footnotetext{
${ }^{1}$ Esta pesquisa foi financiada pelo Conselho Nacional de Desenvolvimento Científico e Tecnológico (CNPq) e pela Coordenação de Aperfeiçoamento de Pessoal de Nível Superior (CAPES/PDEE).

${ }^{2}$ As interações opacas de destaque na Fonologia Lexical (KIPARSKY, 1985) são a contra-alimentação e o contrassangramento. Segundo Matzenauer (2005, p. 41-42), tais processos se referem à relação de ordenamento entre regras. Assim, de acordo com a autora, "[...] se a aplicação de uma regra A criar input
} 
o que se verificou é que processos em princípio considerados estilísticos acabaram por ser convertidos em processos gramaticais à medida que sua atuação passou a ser bastante esperada em determinados contextos. Desse modo, o objetivo principal deste trabalho é analisar tais processos, sobretudo os de sândi, operantes nessas cantigas, a fim de verificar os possíveis condicionamentos linguísticos envolvidos na sua realização.

Entende-se, aqui, como processo não esperado, a regra que deixa de atuar em contextos em que se espera sua aplicação. Dessa forma, a análise será delineada a partir da investigação da obrigatoriedade/não obrigatoriedade da ocorrência desses fenômenos. Assim sendo, para a descrição dos casos de usos estilísticos, presentes no corpus de base desta pesquisa, lançaremos mão do modelo proposto pela Fonologia Lexical (KIPARSKY, 1985), pelo fato de este trazer luz à caracterização de regras consideradas não esperadas, a partir da noção de opacidade.

Dessa maneira, trata-se de verificar se, para suprir necessidades artísticas, o trovador "inventa" ou não um dialeto "literário", usado apenas em contextos específicos e restritos. Compara-se, assim, a aplicação padrão dos processos fonológicos investigados, que remete ao sistema da própria língua, aos usos estilísticos (não esperados), que se baseiam em usos muitas vezes inesperados, que vão contra o sistema estabelecido. O uso estilístico, portanto, é desviante e, enquanto tal, deve receber uma representação que se baseie na noção de "desvio", ou, em outras palavras, "diferente" do "padrão".

Quanto à abrangência do corpus, esta investigação debruça-se sobre o cancioneiro mariano de Afonso X de Castela, o rei "Sábio". Tais cantares encontram-se divididos em cantigas de louvor (cantigas de loor) e cantigas de milagre (cantigas de miragre) e, juntas, formam "um conjunto de 427 cantigas que, descontadas sete repetições internas, se reduzem a 420" (LEÃO, 2007, p. 21). ${ }^{3}$ Todavia, para as finalidades deste estudo, foi feito um recorte do cancioneiro afonsino, sendo coletados, assim, os processos estilísticos atuantes nas cem primeiras cantigas. ${ }^{4}$

para uma regra $\mathrm{B}$, diz-se que $\mathrm{A}$ alimenta $\mathrm{B}$; se, do contrário, a aplicação de $\mathrm{A}$ remover o input de $\mathrm{B}$, e $\mathrm{B}$ não puder ser aplicada, diz-se que A sangra B [...]. Efeitos de contra-alimentação e contra-sangramento são obtidos pela inversão da ordem das regras A e B: A passa a alimentar B e B, a sangrar A.”. Em outras palavras, pode-se inferir que a contra-alimentação é caracterizada pelo fato de uma regra deixar de atuar em ambientes em que se espera sua aplicação. O contrassangramento, ao contrário, caracteriza-se pelo fato de determinada regra ser aplicada, ainda que o contexto não seja favorecedor de sua realização.

${ }^{3}$ Nas cantigas são retratados os milagres da Virgem Maria e os poemas (narrativos, neste caso), de acordo com Mettmann (1986), apresentam quase sempre a mesma estrutura, ou seja, mais de $90 \%$ deles apresentam certa uniformidade. Geralmente, esta estrutura está representada da seguinte maneira: no estribilho (ou refrão) é onde se apresenta "a idéia principal, a lição que se quer passar" (MASSINI-CAGLIARI, 2005, p. 67), e é repetido após cada estrofe; na primeira estrofe (algumas vezes na segunda e na terceira também), há informações que indicam o tempo e o espaço em que se passa a narrativa, além de algumas referências sobre a fonte do milagre. Neste tipo de cantigas (narrativas), também são indicadas as personagens que vivenciam ou presenciam os milagres. Há, entretanto, os chamados louvores (cantigas não narrativas), em que há a predominância dos hinos, e onde a Virgem é celebrada como auxiliadora, medianeira e procuradora (METTMANN, 1986). Ressalta-se, todavia, que as cantigas de milagre são predominantes no cancioneiro afonsino. Conforme Leão (2007), os cantares aparecem em uma proporção de nove por um, isto é, para cada grupo de nove cantigas de milagre, tem-se uma cantiga de louvor, numerada com dezena inteira: "a estruturação das cantigas obedece [...] a um ritmo regular, em que as cantigas de louvor ocupam sempre as dezenas, enquanto as de milagre têm números terminados pelas unidades de um a nove, comparando-se esse sistema, aproximadamente, ao de um rosário" (LEÃO, 2007, p. 24).

${ }^{4} \mathrm{O}$ mapeamento dos processos de sândi considerados não esperados foi realizado a partir do corpus da pesquisa de doutoramento de Cangemi (2014). 
A partir do método de análise desenvolvido e inaugurado no Brasil por MassiniCagliari (1995, 1999), foi realizado o mapeamento e a coleta dos dados das primeiras cem CSM. Essa metodologia parte da observação da estrutura métrico-poética das cantigas, buscando características, sobretudo prosódicas, que apontem para uma melhor caracterização do Português Arcaico (de agora em diante, PA), além de períodos passados de línguas vivas. Nessa perspectiva é que, a seguir, será caracterizado o processo de sândi vocálico externo no PA, bem como os contextos favorecedores de sua aplicação.

\section{Sândi vocálico externo}

De acordo com Xavier e Mateus (1990, p. 327-328), o processo de sândi consiste em um "fenómeno da fonética sintáctica em que um segmento inicial ou final de palavra é afectado pelo contexto em que ocorre, podendo apresentar diferentes realizações que dependem das características do som que antecede ou segue uma fronteira de palavra". Câmara Jr. (1973, p. 341), por sua vez, descreve-o como "mudanças resultantes de assimilações ou dissimilações de um vocábulo em contacto com outro".

Xavier e Mateus (1990, p. 140) definem a elisão como um "fenómeno de fonética sintáctica que consiste na supressão de uma vogal átona final quando a palavra seguinte começa por vogal" (como em linha d'água, cantigas d'amigo; blusa usada-blususada).

Segundo Cunha (1961, p. 27), os três processos de sândi vocálico externo que têm recebido maior relevo na literatura sobre PA são: elisão, hiato e ditongação ("solução entre encontros vocálicos interverbais", segundo o autor). No que diz respeito ao funcionamento destes três processos no PA, Cunha (1961) chega a quatro conclusões de ordem geral e a dez de ordem particular, a saber:

De ordem geral:

a) aos trovadores não repugnavam os hiatos, embora revelassem acentuada inclinação para elidir a vogal do encontro, quando átona;

b) o regime da elisão estava ligado ao ritmo do verso e era contra-regrado por impedimentos fonéticos, fonêmicos e morfológicos;

c) a vogal final átona dos polissílabos perdia-se com mais freqüência que a dos monossílabos;

d) a sinalefa era aparentemente rara.

De ordem particular:

a) a vogal da preposição de só não se elidia antes de vogal quando esta era o corpo do pronome átono o, a, os, as;

b) a vogal dos pronomes átonos me, lhe (ou lhi), se (ou si), xe (ou xi) sempre se elidia antes de outros fonemas vocálicos;

c) a vogal do pronome mi elidia-se antes de palavras iniciadas por e, i e u, mas ditongavase com as vogais a e $o$, quando as precedia;

d) o pronome pessoal oblíquo o (a) combinava-se com as formas pronominais me, te, xe, e lhe, mas, em outros casos, mantinha a sua autonomia silábica;

e) o pronome lo (la) conservava sua vogal quando precedia formas do auxiliar aver, mas podia perdê-la ou não antes de outras palavras de início vocálico;

f) não se elidia nem se yodizava a vogal do pronome e da conjunção que, bem como a das conjunções ca e se;

g) a copulativa e não se ditongava com uma vogal subseqüente;

h) a preposição a contraía-se com o artigo el, mas hiatizava-se com outras palavras iniciadas por vogal; 
i) a vogal átona final de verbo não sofria elisão nem sinalefa quando seguida do pronome $\mathrm{o}(\mathrm{s}), \mathrm{a}(\mathrm{s})$;

j) em caráter exceptivo, admitia-se a fusão silábica de vogal nasal + oral (oral + nasal). (CUNHA, 1961, p. 91-92)

Cunha (1961, p. 42) compara a ditongação (sinalefa) com a elisão, chegando inclusive a afirmar que "são, na verdade, dois aspectos de um mesmo fenômeno". Massini-Cagliari (2005, p. 222) concorda com Cunha (1961) quando ressalta que a questão que se coloca é saber se nos processos de sândi "há ou não contexto para a 'perda' - total (elisão) ou parcial (ditongação) - da 'natureza silábica' da vogal átona da primeira palavra".

Nesse sentido, a oposição que se observa não é entre a elisão e a ditongação, mas, sim, entre estas e o hiato - "não-aplicação do sândi"; "preservação total da "natureza silábica' da primeira vogal” (MASSINI-CAGLIARI, 2005, p. 222):

Como nem todas as vogais que se encontram em posição átona final de palavra são suprimidas ou transformadas em semivogal (isto é, perdem sua "natureza vocálica") diante de uma vogal inicial de outra palavra, uma questão se faz pertinente: seriam os fenômenos de sândi vocálico externo (e, especialmente, a elisão e a ditongação) apenas processos de estilo, a respeito dos quais podiam os trovadores da época optar por aplicálos ou não, fazendo uso deles para chegar à métrica desejada em cada verso? (MASSINICAGLIARI, 2005, p. 222).

Cunha (1961, p. 43) considera improvável que houvesse livre arbítrio da parte dos trovadores e afirma que:

Em relação ao hiato, $80 \%$ dos exemplos que aparecem nos textos examinados são decorrentes de impedimentos fonéticos, fonêmicos e morfológicos. E, dos $20 \%$ restantes, mais de $10 \%$ ainda se explicariam por fenômenos peculiares ao enunciado versificado. A margem de arbítrio - talvez artifício ou qualquer razão não apurada de métrica ou de língua - fica relegada a menos de $10 \%$, ou seja, a uma fração insignificante dos exemplos estudados.

Nesse âmbito, Massini-Cagliari (2005, p. 223) questiona se estamos diante de processos obrigatórios (intrinsecamente linguísticos) ou opcionais (de estilo). A autora considera então necessário confrontar casos de elisão e ditongação com casos de hiato (a partir de um corpus composto por cem cantigas profanas e cinquenta cantigas religiosas).

Diante dos resultados de sua análise, a autora chega à conclusão de que "a elisão é, pois, de modo geral, o processo de sândi mais recorrente nas cantigas medievais galegoportuguesas" (MASSINI-CAGLIARI, 2005, p. 224). A autora constata também uma baixa realização de processos de ditongação no referido corpus e conclui que:

[...] a pouca ocorrência de casos de ditongação como processo de resolução de juntura vocabular dá-se em decorrência do contexto extremamente restrito de sua aplicação: a sinalefa só pode acontecer com os pronomes $m i$ e $t i-\mathrm{e}$ apenas quando seguidos das vogais [a, o, ó]. (MASSINI-CAGLIARI, 2005, p. 226).

Ainda de acordo com os resultados apontados pela autora, praticamente todas as sequências vocálicas podem formar hiatos, no entanto, a elisão, por exemplo, ocorre 
apenas nos contextos em que a vogal átona da primeira palavra é /a/, /e/ ou /o/ (MASSINICAGLIARI, 2005). Segundo sua análise, verifica-se que os casos mais típicos de elisão ocorrem quando a vogal átona da primeira palavra é/e/ ou /o/, como mostram os exemplos (MASSINI-CAGLIARI, 2005, p. 228): ${ }^{5}$

(01) a. do sepulcr' e o demo destroyr (CSM143-26) ${ }^{6}$

sepulcr'e $=$ sepulcro $+\mathrm{e}$

b. Madre quero geuyr ueer (B932-1)

quer'oj'eu $=$ quero + oge + eu

c. se me matassedes ia prazer mia (A285-24)

m'ia $=$ me + ia

d. a guisa d' om' esforçado, quer en guerra, quer en paz. (CSM183-8)

d'om'esforçado $=\mathrm{de}+$ ome + esforçado

Segundo Massini-Cagliari (2005, p. 229), "no caso de /a/, a solução preferida para os encontros vocálicos é o hiato (536 casos, 84.4\%, contra apenas 99 elisões, 15.6\%). Com relação a /e/ e /o/ esta proporção se inverte".

\section{Processos estilísticos de crase, elisão e hiato nas CSM}

De acordo com Massini-Cagliari (2005, p. 230), “os casos de elisão de /a/ diante de vogais diferentes de /a/ mesmo" têm maior ocorrência no corpus das CSM, sendo raros no Cancioneiro da Ajuda e inexistentes no Cancioneiro da Biblioteca Nacional. Essa discrepância levou a autora a considerar, em estudos anteriores, estar diante de dois processos diferentes de sândi, quando a vogal átona da primeira palavra é /a/ e a inicial da palavra seguinte também é /a/; e quando a vogal átona final da primeira palavra é /e/ ou /o/, independentemente da qualidade da vogal seguinte. Nas palavras da autora, "no segundo caso, trata-se do processo clássico de elisão; já no primeiro caso, o processo observado é a crase entre vogais de mesma qualidade" (MASSINI-CAGLIARI, 2005, p. 230). Ainda conforme a autora, tratar este processo como crase (e, não, como elisão ou degeminação) ajuda a explicar por que o hiato é a solução preferida para encontros vocálicos formados pela vogal /a/ seguida de outras vogais, como confirmam os casos abaixo (MASSINI-CAGLIARI, 2005, p. 230):

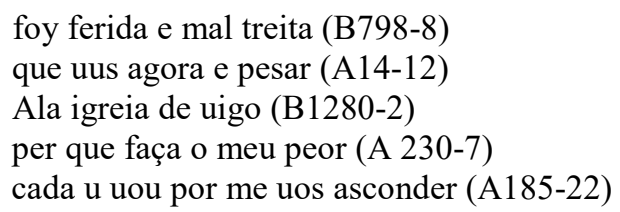

Além da discrepância, a autora notou que "o fato de nem todos os casos de aparente elisão da vogal /a/ respeitarem as restrições rítmicas e fonotáticas a que estão submetidos os casos de elisão de /e/ ou de /o/" serve também como argumento para a sua hipótese de o processo de sândi que atua entre duas vogais /a/ não ser a elisão (MASSINICAGLIARI, 2005, p. 231). ${ }^{7}$ Ainda com relação à crase, Massini-Cagliari (2005, p. 236)

\footnotetext{
5 As abreviaturas A e B se referem, respectivamente, a "Cancioneiro da Ajuda" e a "Cancioneiro da Biblioteca Nacional de Lisboa".

${ }^{6} \mathrm{O}$ primeiro algarismo depois da abreviatura CSM se refere ao número da cantiga; o segundo algarismo, depois a vírgula, designa o verso.

${ }^{7}$ Bisol $(1992,2002)$ também considera que a vogal /a/ tem um comportamento diferenciado no que diz respeito aos processos de sândi vocálico externo no PB: palavras terminadas em /a/ átono final favorecem
} 
afirma que "o argumento crucial a favor da consideração do sândi entre dois 'as' como um processo diferenciado da elisão é o fato de esse fenômeno poder ocorrer quando a vogal final da primeira palavra é tônica.”. Esta hipótese de ser crase (e, não, elisão), estando correta, reduz os casos de elisão mapeados e faz a autora concluir que "uma forte restrição com relação à qualidade da vogal átona final da primeira palavra rege o aparecimento da elisão", pois, para tal, essa vogal deve ser /e/ ou /o/ e salienta que "somente no caso de aproveitamento da elisão como processo estilístico a favor da metrificação do poema esta vogal pode ser /a/" (MASSINI-CAGLIARI, 2005, p. 236).

Para a presente pesquisa, interessa-nos, pois, o processo não esperado, isto é, a regra que deveria ter ocorrido, mas não ocorreu. Nos termos da Fonologia Lexical (KIPARSKY, 1985), diz-se que nos interessa, dessa forma, os processos opacos ou, ainda, casos típicos de contra-alimentação.

A partir dos contextos mapeados por Massini-Cagliari (2005) para o referido fenômeno, foi-nos permitido fazer a coleta dos casos de não realização da crase nas cem primeiras CSM, conforme os exemplos abaixo:

(03) «Serren a eigreja, u non aja al, (CSM 27, 31)

Ca avia y do leyte | da Virgen esperital, (CSM 35, 20)

E desta guisa a Madre de Deus (CSM 52, 35)

$\mathrm{Ca}$ u vermella era, $\tan$ branca a fez $(\mathrm{CSM} 73,55)$

Mais enquant' ela andou (CSM 94, 62)

Assim, por se tratar de um recurso estilístico do trovador, a crase propositadamente não ocorre, ou seja, estamos diante daquilo que não é esperado, a partir do ponto de vista fonológico. Convém ressaltar, pois, que mesmo alguns dos casos considerados não esperados de sândi são, na verdade, bem esperados, porque têm condicionamentos linguísticos - haja vista a pequena margem de manobra que resta para os trovadores, apontada por Cunha (1961, p. 43) e já mencionada anteriormente. Todavia, Massini-Cagliari (2005, p. 254) conclui que o arbítrio de que podiam lançar mão os trovadores é ainda menor do que supôs Cunha, no que concerne ao processo de sândi no PA.

De acordo com a autora, em casos de $/ \mathrm{a} /+/ \mathrm{a} /$ o processo escolhido é a crase. Quando a primeira vogal for o núcleo dos pronomes átonos $m i$ ou $t i$, será a ditongação; nos restantes, mesmo quando a vogal inicial é /i/ (que não em $m i$ ou $t i$ ), será o hiato, isto é, a não aplicação da regra de sândi. No entanto, é possível haver elisão quando a primeira vogal da segunda palavra é tônica, pois a restrição rítmica só leva em conta a tonicidade da vogal da primeira palavra.

Em relação aos monossílabos, a autora afirma que a possibilidade de ocorrência de elisão está mais relacionada com o grau de tonicidade e restrições fonotáticas destes do que propriamente com a quantidade de sílabas das palavras envolvidas. Segundo ela, "os monossílabos tônicos incluem-se entre as palavras que bloqueiam a ocorrência da elisão". É o que ocorre, por exemplo, com as conjunções $e$, que, ca e se (MASSINICAGLIARI, 2005, p. 239).

a degeminação, ao passo que palavras terminadas em outras vogais átonas favorecem a elisão e/ou outro processo de sândi. 
Excetuando o caso de $e$ (que não se elide por restrições de estrutura silábica e não rítmicas), estes elementos, em PA, "não devem ser considerados clíticos fonológicos, uma vez que mantêm sua autonomia" (MASSINI-CAGLIARI, 2005, p. 240). Assim sendo, Massini-Cagliari (2005) inclui igualmente a preposição so na lista já proposta por Cunha (1961).

Desse modo, conclui, então, que os monossílabos estão submetidos à restrição rítmica que regula o aparecimento da elisão. Conclui, ainda, que os tônicos não podem se elidir com as vogais que os seguem, mas que os átonos de vogal /e/ podem. Já os constituídos de apenas uma vogal e os terminados em /i/ estão submetidos a outro tipo de restrições (MASSINI-CAGLIARI, 2005, p. 245).

A autora afirma que, para haver elisão, a vogal deve pertencer a uma sílaba com onset preenchido, pois, de outro modo, temos um hiato. É por isso que monossílabos de uma só vogal "não estão sujeitos à elisão: a sílaba em que se situam tem o onset não preenchido". É o que ocorre com o grupo dos artigos definidos, com os pronomes acusativos, com a preposição $a$ e $a$ e com a conjunção $e$, como mostram os seguintes exemplos (MASSINI-CAGLIARI, 2005, p. 247):

(04) des que leixara a ost' alçando (CSM15-164) servos que tu amas, e quer' a outra leixar. (CSM16-73)

Porque o a Groriosa / achou muy fort' e sen medo (CSM2-37,38)

e que a ajades quant' eu poder punnarei (CSM64-62)

que deu a un seu prelado (CSM2-8)

Nessa perspectiva, a autora conclui ainda que:

[...] enquanto para os monossílabos átonos terminados em /e/ a possibilidade mais freqüente de sândi é a elisão, para os terminados em /i/, o hiato é a solução adotada, com exceção de $m i$ seguido de /a, o, ó/, quando o processo selecionado é a ditongação. Portanto, de todos os processos de sândi possíveis no PA, é a ditongação o que tem o contexto desencadeador mais restrito: apenas ocorre depois do pronome átono $\mathrm{mi}$ (com o pronome $t i$, não é o processo preferencial). (MASSINI-CAGLIARI, 2005, p. 252).

Desse modo, para haver aplicação de sândi, seja por ditongação, crase ou elisão, é necessário que se reúnam as condições morfossintáticas, rítmicas, fonotáticas e fonológicas, caso contrário, dá-se o hiato (MASSINI-CAGLIARI, 2005). MassiniCagliari (2005) ressalta que a fonologia tradicional tem encarado os processos de sândi vocálico externo como casos de ressilabificação, mas que depois de Prince e Somlensky (1993) e Face (1998), "os processos intervocabulares de elisão e ditongação passaram a ser vistos como estratégias de reparação de estruturas silábicas menos perfeitas" (MASSINI-CAGLIARI, 2005, p. 270). Ao analisar os dados de sua pesquisa, baseada na Teoria da Otimalidade - em que a variação interlinguística e a dialetal são fruto de diferentes hierarquias para o mesmo conjunto de restrições -, afirma que as variações estilísticas que se observam nos processos de sândi "devem ser vistas mais como casos de desvios, do que como casos de oposição entre hierarquias" (hierarquia original que gera solução ótima versus hierarquia alternativa que gera desvio, de estilo) (MASSINICAGLIARI, 2005, p. 271).

Para a autora, contudo, não se deve olhar para esse fenômeno como uma questão de "processamento em paralelo", não só porque ambos os usos ocorrem no mesmo contexto, mas, também, porque o falante, ao optar por um uso desviante, tem consciência 
disso. Numa perspectiva otimalista, na visão da autora, pode-se então explicar os usos estilísticos através deste procedimento: o falante faz uma avaliação dos candidatos e identifica o candidato ótimo, entretanto, rejeita-o fazendo uma nova avaliação, para gerar o resultado "artístico" pretendido. Em suma, enquanto o uso "padrão" se assenta em hierarquias "fortes", o uso estilístico, ao contrário, assenta-se em hierarquias "fracas" e desviantes, o que leva a autora a considerar este uso como parte de um dialeto "literário" criado pelo trovador (MASSINI-CAGLIARI, 2005, p. 272).

Como para o presente estudo interessam-nos os casos em que a elisão não deveria ocorrer, mas ocorre, foram mapeados, nas primeiras cem CSM, todos os casos de elisão não esperada. A fim de ilustrar tal processo, observe-se os versos abaixo, extraídos da CSM 4.

(05) e v v $\mathbf{y}^{\prime}$ en un calez bel (CSM 4, 30)

Azari'_e Misahel (CSM 4, 84)

Note-se que a elisão não deveria ter ocorrido nos casos acima destacados, visto que o contexto $(a+$ e) é bloqueador da regra, o que configura um caso típico de contrassangramento. São, ainda, outros casos de elisão não esperada coletados no corpus de base desta pesquisa:

(06) noss' e amparança.» (CSM 9, 140)

Quando est' a conpann' oya (CSM 11, 54)

mató-o dentr' en sa cas' ensserrada (CSM 17, 23)

a un' eigreja, per quant' aprendi, (CSM 17, 56)

Os processos de sândi, conforme aqui descritos, são regras consideradas eminentemente pós-lexicais, visto que operam em fronteira de palavras, ou seja, depois de a palavra já estar formada. De acordo com o modelo da Fonologia Lexical (KIPARSKY, 1985; MOHANAN, 1986; PULLEYBLANK, 1986), que propõe a distinção das regras em lexicais e pós-lexicais, estas últimas não devem ter exceção.

Entretanto, os processos ora considerados como não esperados, que constituem a exceção da regra, também atuam no pós-léxico. Sabendo-se que não é possível propor os dois tipos de regras (esperadas e não esperadas) em um mesmo nível, torna-se pertinente perguntar: como enquadrá-los na gramática da língua?

Para dar conta de tais casos, remetemos à solução proposta por Kiparsky (1985), no que se refere à opacidade das regras. Como já demonstrado, uma regra é considerada opaca não somente quando deixa de atuar em contextos que são favorecedores de sua aplicação - o que configura casos típicos de contra-alimentação -, mas também quando se externaliza sem que haja contexto - como os casos de contrassangramento. Assim sendo, os processos fonológicos descritos nesta investigação como não esperados constituem o grupo das regras opacas em PA, por serem consideradas como desvio (exceção).

Foram mapeados no corpus, todavia, alguns casos que chamamos de "casos especiais de elisão". Sua ocorrência é bastante baixa e configura-se por ser também um processo de elisão não esperada, caracterizado por ter ocorrido a queda da segunda vogal necessária para que a regra de sândi fosse realizada. 
Cangemi e Massini-Cagliari (2012), ao analisarem especificamente estes processos - também nas cem primeiras CSM - concluem que tais casos constituem fenômenos caracterizados pela não ocorrência da vogal inicial da segunda palavra. Esta regra é aplicada, algumas vezes, quando a vogal em questão estiver antes de /s/ - como em nobre spirital (CSM 58, 53). Como é possível observar, segundo as autoras, quando a vogal ocorre, é grafada como $<\mathrm{e}>$, por ser esta a vogal epentética do PA naquele período. Ainda de acordo com Cangemi e Massini-Cagliari (2012), parece haver um "ambiente rítmico comum", no que se refere à não realização dessa vogal epentética, a saber: (i) em contexto de sílaba átona seguida de uma sílaba pretônica; (ii) quando houver monossílabo seguido de uma sílaba pretônica. As autoras, concluem, assim, que as vogais finais da primeira palavra envolvidas no processo são /a/ ou /e/, ao passo que a vogal inicial que não se realiza é sempre /e/ (CANGEMI; MASSINI-CAGLIARI, 2012).

No que concerne à presente análise, os fenômenos caracterizados por Cangemi e Massini-Cagliari (2012) foram mapeados no corpus, conforme os exemplos abaixo:

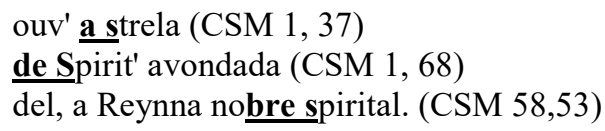

Note-se que, nos três casos, o contexto favorece a aplicação da regra de elisão, no entanto, o onset da segunda sílaba está vazio, o que impede a realização do processo. Portanto, o que se verifica, em casos desta natureza, é a preferência pelo hiato.

Entre todos os processos estilísticos coletados para esta pesquisa, o que apresenta maior realização no corpus é o hiato. Tais casos merecem destaque por serem a "contraparte" da regra de sândi, isto é, por representarem contra-alimentação no processo de elisão. Alguns versos da CSM 36 exemplificam a ocorrência do referido fenômeno:

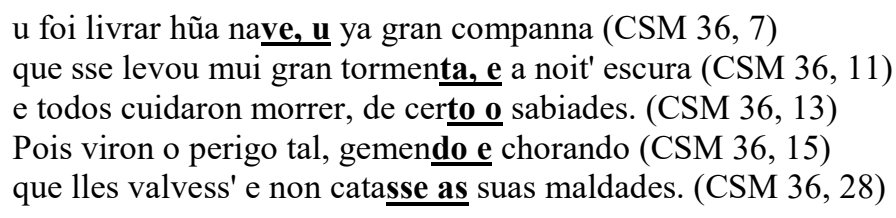

Ressalta-se que, em todos os casos destacados, há o contexto favorecedor da aplicação do processo de elisão. No entanto, ainda assim, a regra deixa de atuar. Desta maneira, a análise quantitativa dos processos de sândi considerados não esperados nas cem primeiras CSM está descrita abaixo, conforme a Tabela 1. É possível notar que os casos de hiato são predominantes $(76,24 \%)$ :

Tabela 1. Processos estilísticos de sândi

\begin{tabular}{c|c|c}
\hline Processos estilísticos de sândi & Cantigas de Santa Maria & $\begin{array}{c}\text { Quantidade } \\
\text { (percentual) }\end{array}$ \\
\hline Hiatos não esperados & 573 & $76,81 \%$ \\
\hline Hiatos não esperados pela não realização da crase & 158 & $21,18 \%$ \\
\hline Elisão não esperada & 9 & $1,21 \%$ \\
\hline Casos especiais de elisão & 6 & $0,8 \%$ \\
\hline TOTAL & $\mathbf{7 4 6}$ & $\mathbf{1 0 0 \%}$ \\
\hline
\end{tabular}


Vale salientar que fizemos a divisão dos processos estilísticos de hiato entre casos de hiato não esperados e casos de hiato não esperados por motivo de cesura do verso, para que obtivéssemos uma descrição mais acurada do fenômeno. A partir deste ponto de vista, o que se pôde verificar é que, quando o verso apresenta cesura, a preferência pelo hiato ocorre em $100 \%$ dos casos, conforme demonstrado nos exemplos abaixo:

(09) se mercee non ll' ouvesse | a comprida de bondade. (CSM 45, 24)

logar en que o fezesse, | e achó-o, com' aprendo, (CSM 45, 38)

mais tornad' a vosso fogo | e nossa alma leixade.» (CSM 45, 54)

ca Deus é mui justiceiro, | e por esto ben sabemos (CSM 45, 57)

E un dos angeos disse: | «O que vos dig' entendede: (CSM 45, 61)

Os dados percentuais, especificamente da realização dos casos de hiato não esperado, estão descritos abaixo, de acordo com a tabela 2:

Tabela 2. Razões do aparecimento dos hiatos não esperados nas CSM

\begin{tabular}{c|c|c}
\hline Realização do hiato & Cantigas de Santa Maria & $\begin{array}{c}\text { Quantidade } \\
\text { (percentual) }\end{array}$ \\
\hline Razões estilísticas & 560 & $76,6 \%$ \\
\hline Cesura & 111 & $15,2 \%$ \\
\hline Presença de vocábulos bloqueadores da elisão & 60 & $8,2 \%$ \\
\hline TOTAL & $\mathbf{7 3 1}$ & $\mathbf{1 0 0 \%}$ \\
\hline
\end{tabular}

Merecem destaque, ainda, alguns casos particulares de hiato não esperado. São aqueles em que a regra de elisão não opera por já ter ocorrido algum outro processo anteriormente. É o que se observa, por exemplo, em deita-la quis per i no infernal (CSM 58,33 ). Neste caso, a preferência é pelo hiato, visto que já houve junção de $e m+o$, originando "no", o que bloqueia a possível elisão seguinte (o + i). Fenômeno semelhante também pode ser observado em a Madre do alto Rey (CSM 59, 8). Embora o contexto favoreça a elisão $(\mathrm{o}+\mathrm{a})$, a opção é pelo hiato, pois já houve a fusão de de+o, impedindo a elisão entre /o/ e /a/. Já em E daquest' un gran miragre oyd' ora, de que fix, nota-se que, do ponto de vista linguístico, o hiato é não esperado. Porém, do ponto de vista poético, a elisão entre oyd'ora pode ter bloqueado a fusão anterior por questões métricas, o que configura a essência do processo estilístico.

Cangemi (2014), ao fazer um mapeamento dos processos de sândi e elisão presentes nas cem primeiras CSM, demonstra também que o fenômeno mais atuante no referido corpus é o hiato. De acordo com a autora, há, no âmbito das cem CSM, 3260 casos de hiato (sílaba CV); 526 casos de hiato com ditongos decrescentes (sílabas VV); e 11 casos de hiato com ditongos crescentes (sílaba VV), totalizando, assim, 3799 casos de hiatização nas primeiras cem CSM. Partindo do estudo realizado pela autora e descontados os 731 casos de hiato não esperado mapeados por esta pesquisa - incluindo, também, aqueles não esperados pela não realização da crase -, conclui-se que a margem de manobra para usos estilísticos é realmente pequena, mas ainda maior do que o percentual apontado por Cunha (1961) e Massini-Cagliari (2005): 19,25\% de todos os casos de hiato, em um primeiro momento, podem ser considerados como processos estilísticos.

Esse percentual da margem de arbítrio dos trovadores (19,25\%) tende, contudo, a diminuir, quando consideramos - no âmbito dos processos de hiato considerados não esperados - certos fatores que convertem tais fenômenos, primeiramente considerados 
estilísticos, em fenômenos gramaticais. É o que ocorre, sobretudo, em posição de cesura do verso. Entretanto, pudemos identificar no corpus um outro fator bloqueador da elisão: a presença das conjunções quando, quanto, como, logo, pero e do substantivo demo, já que em $100 \%$ dos contextos envolvendo tais vocábulos, há a predominância do hiato. Desse modo, ao considerarmos os casos de hiato de cunho puramente estilístico e o total de casos do referido processo - estes mapeados por Cangemi (2014) - concluímos, finalmente, que a margem de manobra que resta para os trovadores é de $14,75 \%$, ou seja, ainda inferior àquela sugerida acima $(19,25 \%)$ e muito próxima da apontada por Cunha (1961), conforme ilustra a Tabela 3:

Tabela 3. Realização do hiato nas CSM.

\begin{tabular}{c|c|c}
\hline Realização do hiato & Cantigas de Santa Maria & $\begin{array}{c}\text { Quantidade } \\
\text { (percentual) }\end{array}$ \\
\hline Hiatos obrigatórios & 3239 & $85,25 \%$ \\
\hline Hiatos de cunho puramente estilístico & 560 & $14,75 \%$ \\
\hline TOTAL & $\mathbf{3 7 9 9}$ & $\mathbf{1 0 0 \%}$ \\
\hline
\end{tabular}

\section{Considerações finais}

Por meio da análise ora empreendida, foi possível caracterizar os processos fonológicos considerados não esperados presentes nas cem primeiras CSM, a fim de verificar os possíveis condicionamentos linguísticos e recursos estilísticos envolvidos em sua realização. Assim, no que se refere aos fenômenos de sândi, com base em Cunha (1961) e Massini-Cagliari (1999, 2005), foram descritos e analisados os contextos de sua aplicação no corpus de base desta pesquisa, visto que esses trabalhos apresentam minuciosa descrição a respeito de sua ocorrência no PA. Foi somente a partir de seus resultados que pudemos conhecer e mapear os processos então considerados não esperados nas CSM.

Nesse sentido, foram caracterizadas as ocorrências consideradas opcionais dos processos de elisão, crase e hiato. O que pode ser verificado, nesse caso, é que os processos estilísticos de hiato foram os fenômenos com maior incidência nesta pesquisa. A observação e a posterior análise do hiato foram fundamentais para o presente estudo, uma vez que este fenômeno caracteriza a contraparte da regra de sândi. Em outras palavras, o hiato representa a regra de elisão que não ocorreu. Dessa forma, a fim de se obter um resultado mais preciso acerca do fenômeno, dividiram-se os casos estilísticos de hiato entre hiatos não esperados e hiatos não esperados por motivo de cesura do verso. Feita a distinção, observou-se que, em contextos de cesura, em 100\% dos casos, a opção é pela hiatização. Ainda com relação aos hiatos não esperados, verificaram-se outros contextos que condicionam sua aplicação, isto é, contextos envolvendo as conjunções quando, quanto, como, pero e logo, assim como o vocábulo demo. Nesses casos, a opção pelo hiato, assim como nos casos de cesura, é absoluta.

Em suma, o que se verifica é que, apesar de muitas vezes o trovador ter de lançar mão de recursos estilísticos para suprir certas necessidades artísticas, o espaço de que dispunham para fazê-lo é praticamente insignificante, dada a mínima margem de manobra deixada para eles. Em outras palavras, pode-se concluir, em última análise, que os trovadores não podiam "criar" um dialeto literário, tão livremente assim, segundo sua vontade, sendo os usos que apresentam, artísticos ou não, desviantes ou não, guiados pela mesma fonologia que guia os demais usos, seus e de outros falantes, da língua. 


\section{REFERÊNCIAS}

BISOL, L. Sândi vocálico externo. In: ILARI, R. (Org.). Gramática do Português Falado. Níveis de Análise Lingüística. 4. ed. revista. v. 2. Campinas: Editora da Unicamp, 2002. p. 19-35.

Sândi vocálico externo: degeminação e elisão. Cadernos de Estudos Lingüísticos, Campinas, n. 23, p. 83-101, jul./dez. 1992.

CÂMARA JR., J. M. Dicionário de filologia e gramática referente à língua portuguesa. 5. ed. Rio de Janeiro: J. Ozon Editor, [1973].

CANGEMI, A. C. F. G. A. Sândi vocálico externo no Português Arcaico. 2014. 210 f. Tese (Doutorado em Linguística e Língua Portuguesa) - Faculdade de Ciências e Letras, Universidade Estadual Paulista "Júlio de Mesquita Filho", Araraquara, 2014.

CANGEMI, A. C. F. G. A.; MASSINI-CAGLIARI, G. Um olhar sobre a vogal epentética no Português Arcaico. In: MAGALHÃES, J. S. (Org.). Linguística in Focus - Fonologia. v. 10. Uberlândia: EDUFU, 2013. p. 181-204.

CUNHA, C. F. Estudos de poética trovadoresca: versificação e ecdótica. Rio de Janeiro: MEC/Instituto Nacional do Livro, 1961.

FACE, T. L. Reexamining Spanish "Resyllabification". Rutgers Otimality Archives.

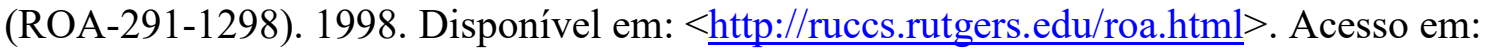
15 mar. 2011.

KIPARSKY, P. Some consequences of Lexical Phonology. In: Phonology Yearbook, 2, p. 85-138, 1985.

LEÃO, Â. V. Cantigas de Santa Maria de Afonso X, o sábio. Aspectos culturais e literários. São Paulo: Linear B; Belo Horizonte: Veredas \& Cenários, 2007.

MASSINI-CAGLIARI, G. A música da fala dos trovadores: estudos de prosódia do português arcaico, a partir das cantigas profanas e religiosas. 2005. 365 f. Tese (Livre Docência em Fonologia) - Faculdade de Ciências e Letras, Universidade Estadual Paulista "Júlio de Mesquita Filho", Araraquara, 2005.

. Do poético ao lingüístico no ritmo dos trovadores: três momentos da história do acento. Araraquara: FCL, Laboratório Editorial, UNESP; São Paulo: Cultura Acadêmica, 1999.

. Cantigas de amigo: do ritmo poético ao lingüístico. Um estudo do percurso histórico da acentuação em Português. 1995. 269 f. Tese (Doutorado em Linguística) Instituto de Estudos da Linguagem, Universidade Estadual de Campinas, Campinas, 1995.

MATZENAUER, C. L. Introdução à teoria fonológica. In: BISOL, L. (Org.). Introdução a estudos de fonologia do português brasileiro. 5. ed. Porto Alegre: EDIPUCRS, 2005. p. 11-81.

METTMANN, W. (Ed.). Cantigas de Santa María (cantigas 1 a 100): Alfonso X, el Sabio. Madrid: Castalia, 1986.

MOHANAN, K. P. The Theory of Lexical Phonology. Dordrecht: D. Reidel Publishing Company, 1986. 
PRINCE, A. S.; SMOLENSKY, P. Optimality Theory: Constraint Interaction in Generative Grammar. Technical Report \#2 of the Rutgers Center for Cognitive Science. Rutgers, Newark, NJ: Rutgers University, 1993.

PULLEYBLANK, D. Tone in Lexical Phonology. Dordrecht: D. Reidel Publishing Company, 1986.

XAVIER, M. F.; MATEUS, M. H. M. (Org.). Dicionário de termos lingüísticos. v. 1. Lisboa: Cosmos, 1990.

Recebido em: 03/10/2017

Aprovado em: 04/05/2018 